\title{
Evaluation of bronchoalveolar cells in pulmonary paracoccidioidomycosis
}

\author{
M.C. Fornazim*, A. Balthazar*, R. Quagliato Jr, R.L. Mamoni*, C. Garcia*, M.H.S.L. Blotta*
}

Evaluation of bronchoalveolar cells in pulmonary paracoccidioidomycosis. M.C. Fornazim, A. Balthazar, R. Quagliato Jr, R.L. Mamoni, C. Garcia, M.H.S.L. Blotta. (C) ERS Journals Ltd 2003.

ABSTRACT: To investigate the local immune response, the cellular infiltrate and cytokine levels were analysed in bronchoalveolar lavage (BAL) from patients with pulmonary paracoccidioidomycosis. The group consisted of 19 patients aged 34-65 yrs. The diagnosis was confirmed by demonstration of the fungus in the sputum or BAL fluid and by serological tests.

Cytospin preparations showed an increased number of lymphocytes and neutrophils in BAL. A higher number of CD8+ lymphocytes were observed in BAL compared with peripheral blood. Alveolar macrophages (AM) expressed approximately three-fold more major histocompatibility class II, intercellular adhesion molecule-1 and B7-2 molecules on their surfaces than their circulating counterparts, indicating that they had differentiated into activated macrophages inside the lungs.

Cultured AM produced higher levels of interleukin (IL)-6, tumour necrosis factor (TNF)- $\alpha$ and macrophage inflammatory protein (MIP)-1 $\alpha$ than peripheral blood monocytes. BAL fluid contained low but detectable amounts of IL-6, TNF- $\alpha$ and MIP$1 \alpha$, and specific antibodies to Paracoccidioides brasiliensis, mainly of the immunoglobulin $\mathbf{G}_{2}$ isotype.

As macrophage inflammatory protein-1 $\alpha$ was shown to selectively attract CD8 $+\mathrm{T}$ cells and this population was elevated in bronchoalveolar lavage, the data suggest that, besides macrophages, CD8 + T-cells may have an important role in the pathogenesis of pulmonary paracoccidioidomycosis.

Eur Respir J 2003; 22: 895-899.
*Dept of Clinical Pathology, Faculty of Medical Sciences, and \# Dept of Internal Medicine, State University of Campinas (UNICAMP) Medical School, Campinas, São Paulo, Brazil.

Correspondence: M.H.S.L. Blotta

Dept of Clinical Pathology

Faculty of Medical Sciences

State University of Campinas (UNICAMP)

PO Box 6111

13083-970 Campinas

São Paulo

Brazil

Fax: 551932893273

E-mail: heblotta@fcm.unicamp.br

Keywords: Bronchoalveolar lavage CD8+ T-cells

interleukin-6

macrophage inflammatory protein- $1 \alpha$

paracoccidioidomycosis

tumour necrosis factor- $\alpha$

Received: November 302002

Accepted after revision: July 182003
Paracoccidioidomycosis (PCM) is a systemic mycosis caused by the dimorphic fungus Paracoccidioides brasiliensis. The disease involves the lungs, mononuclear-phagocytic system and mucocutaneous areas. The infection is caused by inhalation of airborne propagules of the mycelial phase of the fungus, which reach the lungs, eventually evade the host defences and disseminate via the bloodstream and/or lymphatics to virtually all parts of the body $[1,2]$. The mycosis occurs more frequently in males $(80 \%)$, most of them farm workers. Two main clinical forms of the disease are observed, the acute (juvenile) form and the chronic (adult) form. Approximately $90 \%$ of the patients with the adult form present pulmonary involvement [3]. The symptoms are nonspecific and include cough, expectoration, shortness of breath, weight loss, fever and anorexia. It has been shown that phagocytes have an important defence role in the natural resistance to $P$. brasiliensis. Inhaled conidia are phagocytosed by alveolar macrophages (AM) that are responsible for antigen presentation to T-cells and for secreting active substances [4]. Recently, a number of cell surface molecules involved in cell adhesion, costimulation, motility and migration have been recognised $[5,6]$. Cytokines and chemokines have been implicated in the pathophysiology and development of pulmonary diseases, such as tuberculosis and sarcoidosis. Macrophage inflammatory protein (MIP)- $1 \alpha$ is a C-C chemokine induced during inflammation by AM, CD $8+\mathrm{T}$-cells, $\gamma \delta$ T-cells, natural killer (NK) cells and lung epithelium [7]. MIP-1 $\alpha$ is related to the expression of adhesion molecules and the migration of inflammatory cells to the lung. Increased levels of interleukin (IL)-8, MIP- $1 \alpha$ and tumour necrosis factor (TNF)- $\alpha$ are detected in the supernatants of bronchoalveolar cells from patients with sarcoidosis $[8,9]$.

Bronchoalveolar lavage (BAL) represents a valuable clinical laboratory tool for the study of the pathogenesis of pulmonary diseases, and comparison with peripheral blood (PB) permits the identification of selectively recruited leukocyte subsets and the assessment of the influence of the inflammatory microenvironment on their state of activation/differentiation. In this study, the cell populations and cytokine production by AM in comparison with peripheral blood mononuclear cells (PBMC) were investigated. The data reported here suggest the involvement of inflammatory cytokines and MIP- $1 \alpha$ in the local accumulation and activation of cells in the lungs of patients with PCM.

\section{Materials and methods}

\section{Patients}

The group consisted of 19 patients (16 males and three females) ranging in age from 34-65 yrs. Diagnosis was confirmed by demonstration of fungus in the sputum, BAL fluid, or biopsy, in addition to serological tests. Tobacco smoking and alcoholism were associated with the disease in almost all cases. The chest radiograph revealed bilateral and diffuse pulmonary infiltrates. 
The patients were not receiving treatment by the time of the study.

\section{Bronchoalveolar lavage}

Bronchoscopy with BAL were performed as described previously [10]. Lavage was performed using 150-200 mL of saline solution in $25-\mathrm{mL}$ aliquots with immediate vacuum aspiration of each aliquot. The fluid was filtered through sterile gauze into $50-\mathrm{mL}$ conical tubes. The tubes were centrifuged at $400 \times g$ for $10 \mathrm{~min}$ at $4^{\circ} \mathrm{C}$ and the pellets were resuspended in Roswell Park Memorial Institute (RPMI)1640 medium (Sigma Chemical Co., St Louis, MO, USA), followed by Ficoll-Hypaque (Sigma Chemical Co.) gradient separation, as described previously $[11,12]$. The resultant supernatant was concentrated 10 -fold on a 10,000 molecular weight cut-off filter (Amicon, Beverley, MA, USA) under nitrogen. The concentrated supernatant was then divided into $200-\mu \mathrm{L}$ aliquots and rapidly frozen at $-80^{\circ} \mathrm{C}$.

\section{Bronchoalveolar lavage cells analysis}

AM, lymphocytes, neutrophils and eosinophils were differentially counted in a total of 300 cells according to morphological criteria, in cytocentrifuged smears stained with Wright-Giemsa.

\section{Preparation of peripheral blood mononuclear cells}

PBMC were isolated from heparinised venous blood by density centrifugation over Ficoll-Hypaque [11, 12]. After washing three times with phosphate-buffered solution, the mononuclear cells were resuspended $\left(2 \times 10^{6}\right.$ cells $\left.\cdot \mathrm{mL}^{-1}\right)$ in RPMI1640 supplemented with $10 \%$ AB serum, $2 \%$ L-glutamine and antibiotics.

\section{Cell cultures}

BAL cells and PBMC were separately incubated for $90 \mathrm{~min}$ in a $5 \% \mathrm{CO}_{2}$-humidified atmosphere at $37^{\circ} \mathrm{C}$. The nonadherent cells were gently removed. The adherent cells (AM and blood monocytes) were cultivated in 24 -well plates over a period of $18 \mathrm{~h}$ in the presence (or absence) of lipopolysaccharide (LPS; $10 \mu \mathrm{g} \cdot \mathrm{mL}^{-1}$; Sigma Chemical Co.). At the end of the culture period, the supernatants were harvested and immediately frozen at $-80^{\circ} \mathrm{C}$. The cytokine (TNF- $\alpha$, IL- 6 , IL-8, IL-10, IL-12p40 and MIP-1 $\alpha$ ) levels in the cell culture supernatants and BAL fluid were measured by in-house enzyme-linked immunosorbent assays using antibodies from R\&D Systems (Minneapolis, MN, USA).

Flow cytometry analysis of bronchoalveolar lavage cells and peripheral blood mononuclear cells

The commercially available unconjugated monoclonal antibodies (anti-CD4, anti-CD8, anti-CD11b, anti-CD54, anti-human leukocyte antigen (HLA) class II, anti-B7-2) from PharMingen (Heidelberg, Germany) were used. The frequency of BAL cells and PBMC positive for the above reagents was determined by flow cytometry. Fluorescein isothiocyanate anti-mouse immunoglobulin (Ig)G (Sigma Chemical Co.) represented the second-step reagents. Isotypematched mouse monoclonal antibodies were used to set the negative control ( $\operatorname{IgG}_{1}, \operatorname{IgG}_{2 \mathrm{a}}, \mathrm{IgG}_{2 \mathrm{~b}}$; Sigma Chemical Co.). To eliminate nonspecific binding, the cells were initially incubated with heat-inactivated human AB serum. Cells were scored using a fluorescence-activated cell sorter scan analyser (Becton Dickinson, Mountain View, CA, USA) and the data were processed using the Macintosh Cell Quest software program (Becton Dickinson).

\section{Statistical analyses}

Data are presented as mean \pm SEM unless otherwise stated. Group data were compared using the unpaired two-tailed t-test for data that were normally distributed. Data that were not normally distributed were compared using the nonparametric Mann-Whitney U-test. $\mathrm{p}<0.05$ was considered significant.

\section{Results}

Cytospin analysis showed elevated number of lymphocytes $(18.8 \pm 4.2 \%)$ and neutrophils $(5 \pm 1.3 \%)$ in BAL from patients with pulmonary PCM compared with standard reference values for healthy subjects $[10,11,13]$. In these individuals the proportion of CD8+ T-cells in BAL was higher than in $\mathrm{PB}$ (fig. 1), resulting in a decreased $\mathrm{CD} 4 / \mathrm{CD} 8$ ratio (BAL $0.88 \pm 0.3$ and $\mathrm{PB} 1.61 \pm 0.9$ ).

Flow cytometric studies were performed to identify surface markers in AM and PBMC. The proportion of cells expressing major histocompatibility complex (MHC) class II, B7-2, and intercellular adhesion molecule (ICAM)-1 molecules in BAL did not differ significantly from those in PB (fig. 2a). Considering the fluorescence intensity, however, AM expressed approximately three-fold more MHC class II, ICAM-1 and B7-2 on their surfaces than their circulating counterparts, indicating that they had differentiated into AM inside the lungs. Conversely, PBMC expressed approximately two-fold more CD11b than AM.

To evaluate the in vitro production of cytokines, cell-free supernatants were obtained from AM or PBMC short-term cultures and tested for the presence of IL-6, TNF- $\alpha$, MIP- $1 \alpha$, IL-12p40 and IL-8. The early time point (18 h) was chosen to permit the analysis of cytokines that were being actively expressed in vivo (media condition) and to reveal the cytokine profile of cells that were previously activated and differentiated in vivo in response to infection with $P$. brasiliensis.



Fig. 1. - Per cent of CD4+ $(\bigcirc)$ and $\mathrm{CD} 8+(\bullet)$ T-cells in bronchoalveolar lavage (BAL) and peripheral blood (PB) of patients with pulmonary paracoccidioidomycosis. Horizontal lines indicate mean values. ${ }^{\#}$ : $\mathrm{p}=0.0001 \mathrm{BAL} \mathrm{CD} 8+$ versus $\mathrm{PB} \mathrm{CD} 8+$. 

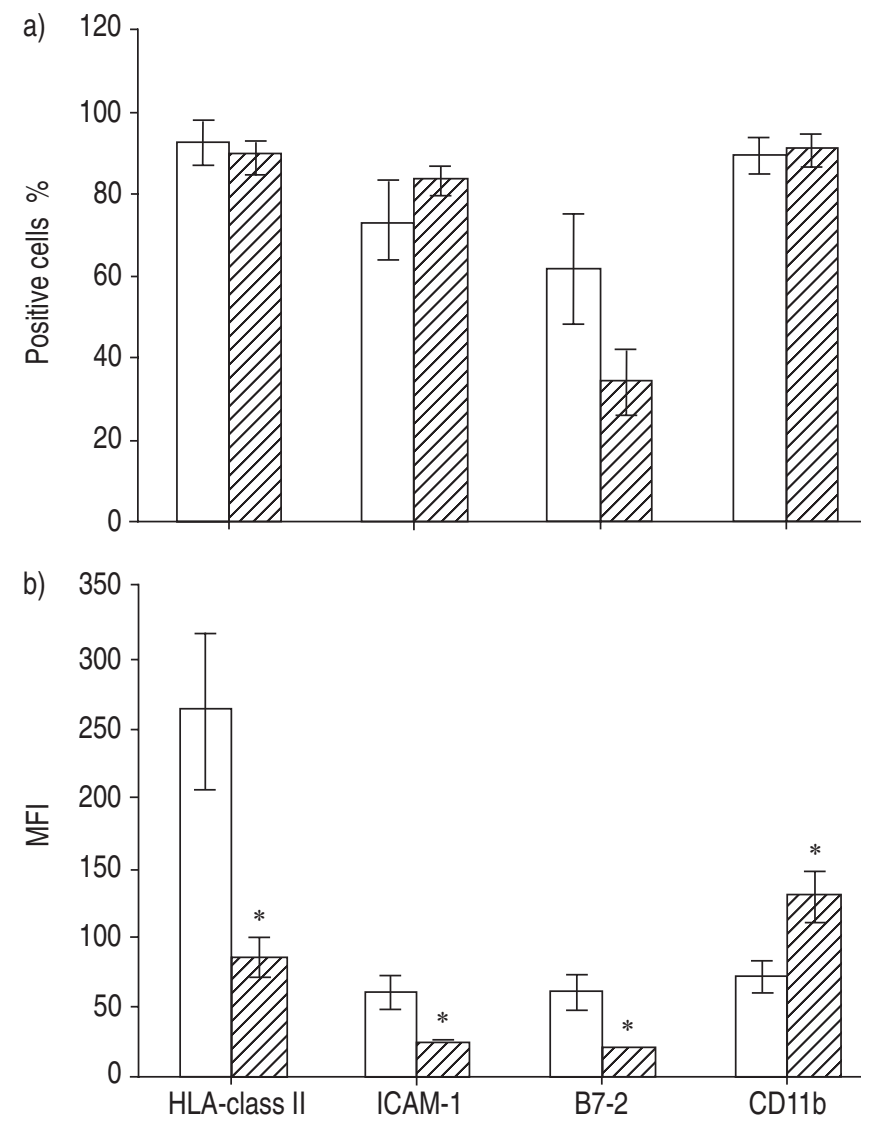

Fig. 2.-Flow cytometric analysis of surface markers of alveolar macrophages $(\square)$ and peripheral blood monocytes $(\mathbb{Z})$ from patients with pulmonary paracoccidioidomycosis. a) Shows the percentage of positive cells, and b) shows mean fluorescence intensity (MFI). Values are expressed as mean \pm SEM. HLA: human leukocyte antigen; ICAM: intercellular adhesion molecule. *: $\mathrm{p}<0.05$ versus alveolar macrophages.

Markedly elevated levels of MIP- $1 \alpha$ were found in BAL fluid and AM supernatants compared with PBMC supernatants. Moreover, AM also produced more IL- 6 and TNF- $\alpha$ than did PBMC (fig. 3). Stimulation with LPS resulted in significant increases of MIP-1 $\alpha$, TNF- $\alpha$ and IL- 6 concentration in cultures of both AM and PBMC (data not shown).

The spontaneous production of IL-12p40 was low and not significantly different between BAL and PBMC cultures, but after stimulation with LPS, this production was higher in AM (fig. 4). AM and PBM spontaneously produced high amounts of IL-8 (3,051 \pm 501 versus $3,015 \pm 573 \mathrm{pg} \cdot \mathrm{mL}^{-1}$, respectively) and stimulation with LPS resulted in a small increase (data not shown).

BAL fluid from PCM patients contained low but detectable levels of IL- 6 , TNF- $\alpha$ and MIP- $1 \alpha$, and specific antibodies to P. brasiliensis, mainly of the $\mathrm{IgG}_{2}$ isotype (data not shown).

\section{Discussion}

The analysis of BAL cells of patients with pulmonary PCM showed an increased number of lymphocytes and neutrophils. BOSCARDIN et al. [13] also described a neutrophilic alveolitis in six patients with PCM. However, an important fact to be taken into consideration is that, in both studies, the majority of the patients were smokers, and the correlation between smoking and neutrophil influx into the lungs is well known [14]. Conversely, the impressive increase in lymphocyte

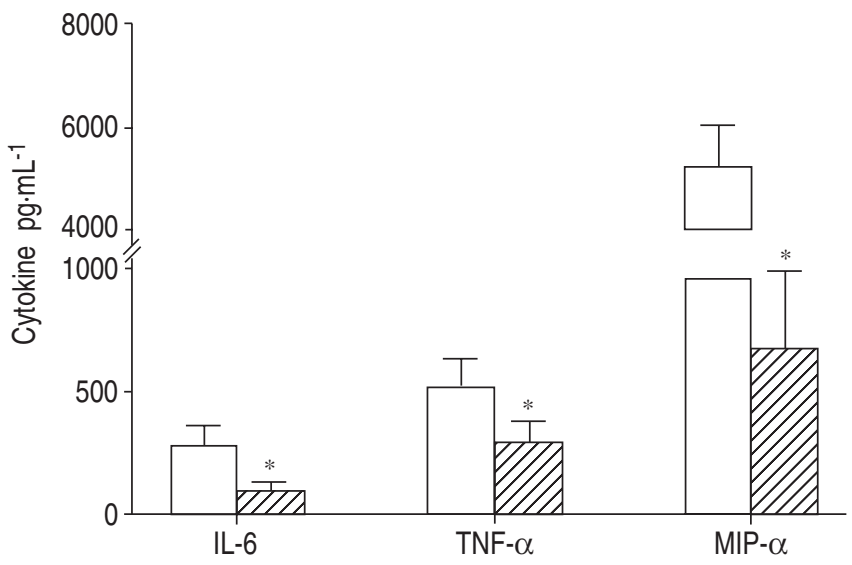

Fig. 3.-Cytokine production by alveolar macrophages $(\square)$ and peripheral blood monocytes $(\mathbb{Z})$ from patients with pulmonary paracoccidioidomycosis. Values are expressed as mean \pm SEM. IL: interleukin; TNF: tumour necrosis factor; MIP: macrophage inflammatory protein. ${ }^{*}: \mathrm{p}<0.05$ versus alveolar macrophages.

number, also observed by CARVALHO et al. [15] in BAL of patients with PCM is probably a result of the fungal infection itself.

$\mathrm{AM}$ are believed to be important in the initial containment of the microorganisms through nonspecific or natural immune mechanisms. AM also phagocytose particles and microbial organisms and carry them via lymphatics to regional hilar lymph nodes, where specific immune responses are believed to


Fig. 4. - Interleukin (IL)-12p40 production by alveolar macrophages (AM) and peripheral blood monocytes (PBM) from patients with pulmonary paracoccidioidomycosis, cultured in medium alone or with lipopolysaccharide (LPS). Each line represents one patient. *: $p<0.05$. 
be generated. Thus, AM may be involved in specific immune responses to $P$. brasiliensis both as accessory cells and as targets of cytotoxic T-lymphocytes in the regional lymph nodes. The expression of HLA class II, B7-2 and ICAM-1 in $\mathrm{AM}$ is indicative of a preserved and active macrophage function in patients with PCM. ICAM-1 (CD54) plays an important role in the extravasation of leukocytes and in other cellular functions, such as cytotoxicity, phagocytosis, chemotaxis and induction of lymphocyte proliferation. The activation molecule MHC class II as well as B7-2 is essential for the macrophage antigen-presenting cell function.

The expression of activation, costimulatory and adhesion molecules is directly influenced by the cytokines present in the milieu where the inflammatory response takes place. In this report, the authors were able to demonstrate that cultured AM spontaneously produced higher levels of IL- 6, TNF- $\alpha$, and MIP- $1 \alpha$ compared with PBMC. BAL fluid from PCM patients also contained detectable levels of IL-6, TNF- $\alpha$ and MIP- $1 \alpha$. In a previous paper, the detection of IL- 6 , TNF- $\alpha$ and MIP- $1 \alpha$ was reported in serum from patients with PCM [16]. TNF- $\alpha$ has been shown to be a critical mediator of innate immunity against several respiratory pathogens. Its activities include stimulation of neutrophils for enhanced protein release and respiratory burst, and enhancement of their phagocytic and killing activity. TNF- $\alpha$ is also required for macrophage accumulation and differentiation into epithelioid cells and for the persistence of well-formed granulomas [17], a common finding in lung biopsies from patients with pulmonary PCM. In human [18] and murine [19-21] PCM, the protective role of TNF- $\alpha$ and interferon (IFN)- $\gamma$ was associated with an efficient macrophage response to the infection.

IL-12 is a critical cytokine that stimulates IFN- $\gamma$ production and proliferation of activated T-cells and NK cells. Enhanced production of IL-12 by lung macrophages was demonstrated in sarcoidosis [22]. It was found that AM from patients with PCM are able to produce more IL-12 than PBMC, indicating a local immune response to the fungus in the lungs.

Lymphocytes are the other major immune effector cells found in the lung alveoli. Trafficking of these lymphocytes also occurs between hilar lymph nodes and alveolar spaces. MIP- $1 \alpha$ is a C-C chemokine induced by AM, T-cells, NK cells and lung epithelium during inflammation. MIP- $1 \alpha$ was shown to promote chemotaxis of lymphocytes selectively recruiting CD8+ T-cells [23-25]. The reported finding of an increased number of CD8+ in PCM BAL supports the notion that MIP- $1 \alpha$ is important in attracting and stimulating this subpopulation. A protective role for CD8+ T-cells has been suggested in experimental PCM since its depletion induces a more severe and/or disseminated disease in both resistant and susceptible mice [26]. Cytotoxic CD8+ T-cells represent a major defence against intracellular pathogens by the production of IFN- $\gamma$ and cytolytic activity, and may be involved in the clearance of $P$. brasiliensis cells. Recently, a great deal of attention has been dedicated to the role of CD8+ T-cells in tuberculosis, particularly with regard to protective immunity $[27,28]$. Clinical studies have shown that significantly lower percentages of BAL CD3+CD8+ T-lymphocytes were detected in patients with far-advanced pulmonary involvement compared with those with minimal pulmonary involvement [29]. These data suggest that, in addition to CD4+ T-cells, CD8+ T-cells may have an important role in the outcome of pulmonary tuberculosis. In experimental cryptococcosis, it was demonstrated that $\mathrm{CD} 8+\mathrm{T}$-cells are required for maximal recruitment of CD4+ T-cells into the lungs and IFN- $\gamma$ production, which play a role in macrophage activation and development of protective T-helper cell-type 1 CD4+ T-cells [30].

To conclude, these findings suggest that alveolar macrophages are activated within the proinflammatory environment created by the fungus in the lungs of patients with paracoccidioidomycosis. This activation is demonstrated by the elevated expression of adhesion and costimulatory molecules as well as by the ex vivo production of interleukin-6, tumour necrosis factor- $\alpha$ and macrophage inflammatory protein- $1 \alpha$. The high detection of macrophage inflammatory protein- $1 \alpha$ in bronchoalveolar lavage fluid and alveolar macrophage supernatants indicates a potential role of this chemokine in regulating the migration and activation of inflammatory cells, including CD8+ T-cells, toward sites of the Paracoccidioides brasiliensis inflammatory process. The confirmation of a protective role of $\mathrm{CD} 8+\mathrm{T}$-cells and macrophage inflammatory protein- $1 \alpha$ in pulmonary paracoccidioidomycosis would provide means to explore this component of the immune system in order to improve conventional therapy with antifungals, and perhaps lead to the production of preventive and therapeutic vaccines.

\section{References}

1. Franco M. Host parasite relationship in paracoccidioidomycosis. J Med Vet Mycol 1987; 25: 5-18.

2. McEwen JG, Bedoya V, Patino MM, Salazar ME, Restrepo A. Experimental murine paracoccidioidomycosis induced by the inhalation of conidia. J Med Vet Micol 1987; 25: 165-175.

3. Brummer E, Castaneda E, Restrepo A. Paracoccidioidomycosis: an update. Clin Microbiol Rev 1993; 6: 89-117.

4. Cano LE, Arango R, Salazar ME, Brummer E, Stevens DA, Restrepo A. Killing of $P$. brasiliensis conidia by pulmonary macrophages and the effect of cytokines. J Med Vet Mycol 1992; 30: 161-168.

5. Larson S, Springer TA. Structure and function of leukocyte integrins. Immunol Rev 1990; 114: 181-217.

6. Allison JP. CD28-B7 interactions in T-cell activation. Curr Opin Immunol 1994; 6: 414432.

7. Adams DH, Lloyd AR. Chemokines: leucocyte recruitment and activation cytokines. Lancet 1997; 349: 490-495.

8. Ziegenhagen MW, Schurum S, Zissel G, Zipfel PF, Schlaak M, Muller-Quernheim J. Increased expression of proinflammatory chemokines in bronchoalveolar lavage cells of patients with progressing idiopathic pulmonary fibrosis and sarcoidosis. J Invest Med 1998; 46: 223-231.

9. Takizawa H, Satoh M, Okazaki H, et al. Increased IL-6 and IL-8 in bronchoalveolar lavage fluids (BALF) from patients with sarcoidosis: correlation with the clinical parameters. Clin Exp Immunol 1997; 107: 175-181.

10. Goldstein RA, Rohatgi PK, Bergofsky EH, et al. Clinical role of bronchoalveolar lavage in adults with pulmonary diseases. Am Rev Respir Dis 1990; 142: 481-486.

11. Ettensohn DB, Jankowski MJ, Duncan PG, Lalor PA. Bronchoalveolar lavage in the normal volunteer subject. I. Technical aspects and intersubject variability. Chest 1988; 94 : 275-280.

12. Daniele RP, Elias JA, Epstein PE, Rossman MD. Bronchoalveolar lavage: role in the pathogenesis, diagnosis, and management of interstitial lung diseases. Ann Intern Med 1985; 102: 93-108.

13. Boscardin RN, Brandão H, Balla A. Bronchoalveolar lavage findings in pulmonary paracoccidioidomycosis. $\mathrm{J}$ Med Vet Mycol 1985; 23: 143-146.

14. Goldstein RA, Rohatgi PK, Bergofsky EH, et al. Clinical role of bronchoalveolar lavage in adults with pulmonary disease. Am Rev Respir Dis 1990; 142: 481-486.

15. Carvalho CRR, Kairalla RA, Carvalho-Filho RS, et al. O lavado broncoalveolar nas pneumopatias intersticiais pulmonares. [Bronchoalveolar lavage in the interstitial lung diseases]. Rev Hosp Clin Fac Med Univ São Paulo 1987; 42: $110-114$.

16. Mamoni RL, Nouer SA, Oliveira SJ, et al. Enhanced production of specific IgG4, IgE, IgA and TGF-beta in 
sera from patients with the juvenile form of paracoccidioidomycosis. Med Mycol 2002; 40: 153-159.

17. Shikama Y, Koabyashi K, Kasahara K, et al. Granuloma formation by artificial macroparticles in vitro: macrophages and monokines play a critical role in granuloma formation. Am J Pathol 1989; 134: 1189-1199.

18. Oliveira SJ, Mamoni RL, Musatti CC, Papaiordanou PM, Blotta $\mathrm{MH}$. Cytokines and lymphocyte proliferation in juvenile and adult forms of paracoccidioidomycosis: comparison with infected and non-infected controls. Microb Infect 2002; 4: 139-144.

19. Cano LE, Kashino SS, Arruda C, et al. Protective role of gamma interferon in experimental pulmonary paracoccidioidomycosis. Infect Immun 1998; 66: 800-806.

20. Souto JT, Figueiredo F, Furlanetto A, Pfeffer K, Rossi MA, Silva JS. Interferon- $\gamma$ and tumor necrosis factor- $\alpha$ determine resistance to Paracoccidioides brasiliensis infection in mice. Am J Pathol 2000; 156: 1811-1820.

21. Nascimento FRF, Calich VLG, Rodríguez D, Russo M. Dual role for nitric oxide in paracoccidioidomycosis: essential for resistance, but overproduction associated with susceptibility. J Immunol 2002; 168: 4593-4600.

22. Shigehara K, Shijubo N, Ohmichi M, et al. IL-12 and IL-18 are increased and stimulate IFN- $\gamma$ production in sarcoid lungs. J Immunol 2001; 166: 642-649.

23. Serody JS, Burkett SE, Panoskaltsis-Mortari A, et al. T-lymphocyte production of macrophage inflammatory protein- $1 \alpha$ is critical to the recruitment of CD8+ T cells to the liver, lung, and spleen during graft-versus-host disease. Blood 2000; 96: 2973-2980.

24. Schall TJ, Bacon K, Camp RDR, Kaspari JW, Goeddel DV. Human macrophage inflammatory protein- $\alpha$ (MIP-1 $\alpha)$ and MIP-1 $\beta$ chemokines attract distinct populations of lymphocytes. J Exp Med 1993; 177: 182.

25. Denis M. Proinflammatory cytokines in hypersensitivity pneumonitis. Am J Respir Crit Care Med 1995; 151: 164-169.

26. Cano LE, Singer-Vermes LM, Costa T, et al. Depletion of $\mathrm{CD} 8 \mathrm{~T}$ cells in vitro impairs host defense of mice resistant and susceptible to pulmonary paracoccidioidomycosis. Infect Immun 2000; 68: 352-359.

27. Smith SM, Dockrell HM. Role of CD8 T cells in mycobacterial infections. Immunol Cell Biol 2000; 78: 325333.

28. Mazzaccaro RJ, Stenger S, Rock KL, et al. R. Cytotoxic T lymphocytes in resistance to tuberculosis. Adv Exp Med Biol 1998; 452: 85-101.

29. Tsao TCY, Chen CH, Hong J, Hsieh M, Tsao K, Lee C. Shifts of T4/T8 $\mathrm{T}$ lymphocytes from BAL fluid and peripheral blood by clinical grade in patients with pulmonary tuberculosis. Chest 2002; 122: 1285-1291.

30. Huffnagle GB, Lipscomb MF, Lovchic JA, Hoag KA, Street NE. The role of CD4+ and CD8+ T cells in the protective inflammatory response to a pulmonary cryptococcal infection. J Leuk Biol 1994; 55: 35-42. 